\title{
Determination of the optimal culture medium and salts for bioassays with neotropical halophilic cladocerans
}

\author{
Vignatti Alicia M., Cabrera Gabriela C., Echaniz Santiago A. \\ Facultad de Ciencias Exactas y Naturales, Universidad Nacional de La Pampa, Santa Rosa, La Pampa, República Argentina.
}

\section{Email address:}

aliciavignatti@exactas.unlpam.edu.ar (Vignatti A. M. )

\section{To cite this article:}

Vignatti Alicia M., Cabrera Gabriela C., Echaniz Santiago A. Determination of the Optimal Culture Medium and Salts for Bioassays with Neotropical Halophilic Cladocerans. American Journal of Life Sciences. Vol. 2, No. 2, 2014, pp. 40-45. doi: 10.11648/j.ajls.20140202.11

\begin{abstract}
The neotropical halophilic cladocerans Daphnia menucoensis and Moina eugeniae are common in shallow lakes of semi-arid central and northern Patagonia in Argentina. In the present study, we determined the tolerance of neonates of both species to salinity and different concentrations of $\mathrm{Cl}^{-}$and $\mathrm{SO}_{4}{ }^{2-}$. However, the responses differed according to the demineralized water or groundwater employed to dissolve the salts. On the other hand, survival was lower when using analytical grade reagents instead of natural salts. As bioassays should be developed to determine the chronic physiological responses of both species, the objectives of this study were to compare three culture media and test the hypothesis that natural salts dissolved in aquifer water is the optimal combination for breeding. Acute bioassays were conducted with neonates of both species. To compare the media, $\mathrm{NaCl}$ solutions $\left(5,10,15,20\right.$ and 25 g. $\left.\mathrm{L}^{-1}\right)$ were prepared using demineralized water, aquifer water and EPA medium. For the second objective, solutions of equal concentrations were prepared with salts obtained from the natural environment, previously sterilized, and dissolved in phreatic water. Survival was higher in the aquifer water, whose chemical composition was relatively more representative of the lakes inhabited by both species. It was almost complete at 20 and $15 \mathrm{~g}$. $\mathrm{L}^{-1}$ for D. menucoensis and M. eugeniae, respectively. Lower survival of D. menucoensis was found in EPA medium, although it was developed for breeding other species of Daphnia. In the second series of bioassays, survival was almost complete until 20 g.L $\mathrm{L}^{-1}$ (D. menucoensis) and 25 g.L $\mathrm{L}^{-1}$ (M. eugeniae). The combination natural salts/aquifer water was adequate to assess the tolerance of both cladocerans. However, the former was more important, since the results were consistent with previous studies when these salts were dissolved in demineralized water. In addition, survival was much higher than when we used salts of analytical grade.
\end{abstract}

Keywords: Bioassays, Daphnia Menucoensis, Moina Eugeniae, Halophilic Cladocerans Culture, Salinity Tolerance

\section{Introduction}

The zooplankton of lakes of central Argentina is characterized by numerous endemic Neotropical crustaceans $[1,2,3]$. Although their distribution patterns are known and information on the ecosystems they inhabit is available $[1,4$, $5,6,7]$, the ecophysiological information on their environmental requirements is very scarce in order to collaborate to understand their distribution.

In the semiarid central region of the country and northern Patagonia, there are numerous temporary shallow lakes with relatively high salinity. Its zooplankton is characterized by a frequent association of endemic halophilic cladocerans, among which Daphnia menucoensis and Moina eugeniae (Fig. 1) are the most important [1, 8, 9, 10]

The presence of one species of the genus Daphnia is interesting, since the members of this taxon are relatively scarce in saline ecosystems $[11,12,13]$. This genus may have originated in freshwater where it is more widely distributed $[14,15]$. However, halophilic species such as $D$. mediterránea, with a circummediterranean distribution and D. salina with a Nearctic distribution have been recorded.

Through field studies, it has been determined that $D$. menucoensis can inhabit water bodies with salinity up 29.7 g.L ${ }^{-1}$ [16]. Its presence makes a difference between saline ecosystems in Argentina and elsewhere, because this species is able to strongly modify the characteristics of the lakes that it inhabits. In the absence of fish predation that may exclude it from aquatic ecosystems, it has been determined that its large size and high filtration efficiency endow it with a high grazing rate for phytoplankton. This means that the lakes it inhabits will be clear, with low chlorophyll- $a$ concentrations and high water transparency [11], despite being hypertrophic $[8,17]$. 


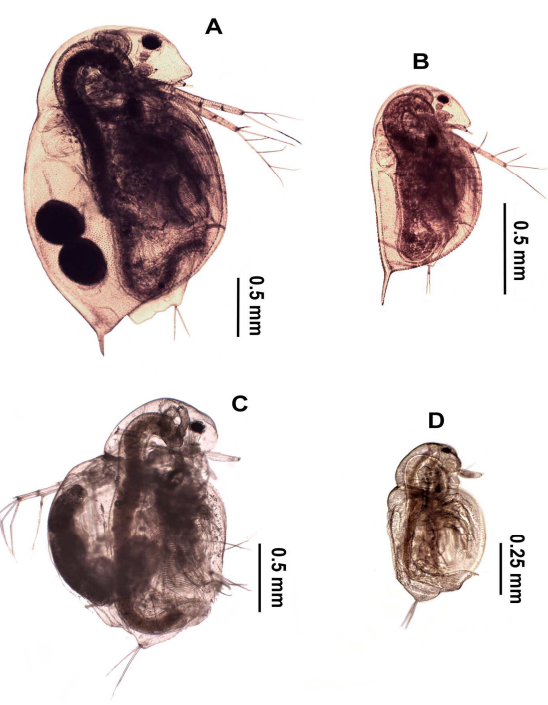

Figure 1. Neotropical cladocerans used in bioassays. A and B: Daphnia menucoensis (parthenogenetic female and neonate). $C$ and D: Moina eugeniae (parthenogenetic female and neonate).

In the case of the genus Moina, halophilic species are more common, such as $M$. mongolica whose distribution extends from northern Africa, eastern and central Europe to Mongolia [18], M. salina with a circummediterranean distribution [18, 19], M. baylyi in Australia [18] and $M$. hutchinsoni in North America [20]. In the lakes of Argentina in which $M$. eugeniae has been recorded, the maximum salinity was 48.3 g. $\mathrm{L}^{-1}$ [21]. Although its influence on the characteristics of water bodies is not as marked as that of $D$. menucoensis, it has not been registered in water bodies containing zooplanktivorous fish; as it is one of the species of this genus that reaches a relatively large size, it is easily predated on.

At present, experimentally obtained information exists on the negative effects of salinity on different population parameters of some species of both genera from other regions such as Daphnia magna [22, 23, 24], Daphnia carinata [25], Daphnia exilis [26], Moina hutchinsoni [27], Daphnia pulex, and Moina macrocopa [28]. However, in the case of the two Argentine species, although many aspects of their biology in natural conditions are known $[8,9,29,30$, 31 ], at present, only acute bioassays have been performed to determine the tolerance of their neonates to salinity [32] or the effects of different concentrations of anions such as $\mathrm{Cl}^{-}$ and $\mathrm{SO}_{4}{ }^{2-}[33]$; because these are the predominant anions in most of the lakes in which these species have been recorded [16].

During these bioassays, it was observed, on the one hand, that the response of both species could vary according to the medium in which the salts were dissolved, i.e. whether it was demineralized water or groundwater. Moreover, we found that the survival of neonates of both species was considerably lower when using pure salts of analytical grade instead of natural salts [33].

Taking into account that we will have to develop chronic bioassays at the National University of La Pampa to determine the physiological response (longevity, fecundity, number of molts, changes in size, etc.) of D. menucoensis and $M$. eugeniae under different salinities, we have posed some questions on the efficiency of the dissolution media and the type of solute to be employed. Therefore, the aims of this study were: i) to evaluate and compare the efficiency of three different culture media at different salinities: demineralized water, the groundwater underlying the city of Santa Rosa and EPA medium or "reconstituted water" (one of the most widely used media in standard ecotoxicological bioassays) and ii) to test the hypothesis that the combination of natural salts dissolved in phreatic water is the optimal combination to determine the tolerance to salinity in both species. This was done in order to determine the most appropriate culture medium and best salts for future bioassays.

\section{Material and Methods}

Acute bioassays were carried out with neonates of both species (younger than $24 \mathrm{~h}$ old), taking into account as the effect of the studied variable the immobility and death of the individuals.

To obtain organisms to carry out the bioassays, sediment from the dried bottom of a saline lake was collected in La Pampa province in 2006. Daphnia menucoensis and Moina eugeniae generally integrate the zooplankton of this lake during hydrophases. The sediment was placed in a $300 \mathrm{~L}$ water tank outdoors. The physiochemical characteristics of the water were relatively similar to those of the original lake where the species were recorded. Once both populations had developed and established from the ephippia of the "egg bank", parthenogenetic females were removed and were separately acclimatized in the laboratory in two $20 \mathrm{~L}$ aquaria for 90 days. From these aquaria, several females were selected and kept in containers with a volume of $200 \mathrm{~mL}$. Neonates which were born from the selected females were used for the bioassays.

To carry out the first objective, solutions were prepared with $5,10,15,20$ and 25 g.L. $\mathrm{L}^{-1} \mathrm{NaCl}$ of analytical quality, dissolved in demineralized water, groundwater from the aquifer underlying Santa Rosa ("aquifer") (Table 1), sterilized by heat, and EPA medium or "reconstituted water" [34] Five replicates per treatment were performed, comprising five neonates each and were checked every $12 \mathrm{~h}$.

To meet the second objective, solutions were prepared with $5,10,15,20$ and 25 g. $\mathrm{L}^{-1}$ of natural salts. The salts were obtained after its precipitation during the drying of a lake in which both species were recorded during the previous hydrophase. This salt, previously sterilized by heat, was dissolved in water from the aquifer underlying the city of Santa Rosa. These bioassays were also set up with five neonates, but four replicates for each salinity level were prepared. In this case, they were checked every $24 \mathrm{~h}$.

The bioassays were carried out in $20 \mathrm{~mL}$ glass tubes for 48 $\mathrm{h}$ without food or renewal of the medium. Neonates were exposed to a photoperiod of 8:16 $\mathrm{h}$ darkness: light. The 
lighting was provided by two 18 Watt fluorescent tubes and the temperature remained constant at $22 \pm 1{ }^{\circ} \mathrm{C}$.

To determine differences between the treatments, the Kruskal Wallis non-parametric test $[35,36]$ and the Mann-Whitney test [37] were performed.

Table 1. Chemical composition of the aquifer water. All the values (except pH) are expressed in mg. $L^{-1}$. TDS: total dissolved solids.

\begin{tabular}{cc}
\hline TDS & $\mathbf{1 9 4 0}$ \\
\hline $\mathrm{pH}$ & 8.02 \\
$\mathrm{CO}_{3}{ }^{2-}$ & 0 \\
$\mathrm{HCO}_{3}{ }^{-}$ & 200 \\
$\mathrm{Cl}^{-}$ & 409.4 \\
$\mathrm{SO}^{-}$ & 660 \\
$\mathrm{Ca}^{2+}$ & 104 \\
$\mathrm{Mg}^{2+}$ & 37.9 \\
$\mathrm{~K}^{+}$ & 12 \\
$\mathrm{Na}^{+}$ & 473 \\
$\mathrm{~F}^{+}$ & 2.27 \\
$\mathrm{As}^{2-}$ & 0.1 \\
$\mathrm{NO}_{3}{ }^{2-}$ & 31 \\
$\mathrm{NO}_{2}{ }^{+-}$ & 0.009 \\
$\mathrm{NH}_{4}{ }^{+}$ & 0 \\
\hline
\end{tabular}

\section{Results}

\subsection{Evaluation of the Efficiency of Three Different Culture Media}

Significant differences between the tested media were found in the case of $D$. menucoensis $(\mathrm{H}=19.38$; $\mathrm{p}=0.0001)$. Survival was very low in bioassays with EPA medium, since the mean survival of neonates was 2.25 and 0.75 at 5 and 10 g.L ${ }^{-1}$ (Fig. 1). Survival was higher in bioassays with demineralized water, as survival was greater at these two concentrations; however, at 15 g. $\mathrm{L}^{-1}$ only a mean of 0.25 neonates survived (Fig. 2). Finally, survival was much higher in the treatments with aquifer water, since it was almost complete up to $20 \mathrm{~g} . \mathrm{L}^{-1}$. However, no live neonates were registered in the highest concentration $\left(25\right.$ g.L $\left.{ }^{-1}\right)$ (Fig. 2).

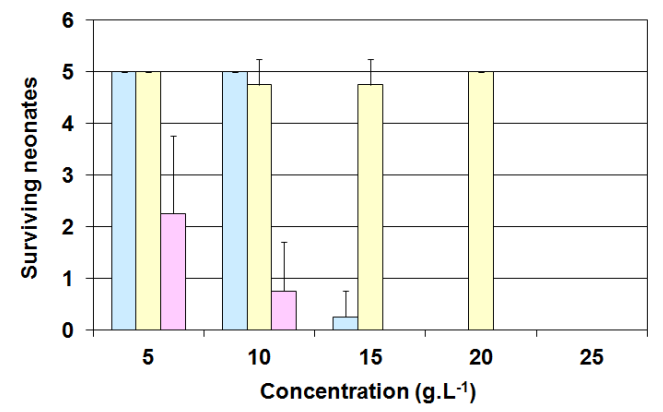

$\square$ Demineralized water $\square$ Aquifer water $\square$ EPA medium

Figure 2. Results of bioassays with D. menucoensis and increasing concentrations of $\mathrm{NaCl}$ dissolved in three different culture media.

The results of bioassays with $M$. eugeniae were also different $(H=12.67 ; p=0.0315)$ and survival of neonates was very low in all three media. No specimens survived for $48 \mathrm{~h}$ in EPA medium, even at the lowest concentration (Fig. 3). In bioassays with demineralized water, survival was complete at $5 \mathrm{~g} . \mathrm{L}^{-1}$, but no neonates survived in treatments above this concentration (Fig. 3). In the treatments with aquifer water, a mean of 3.75 and 0.5 neonates survived at 10 and 15 g. $\mathrm{L}^{-1}$, respectively, but none at the two highest concentrations (Fig. 3).

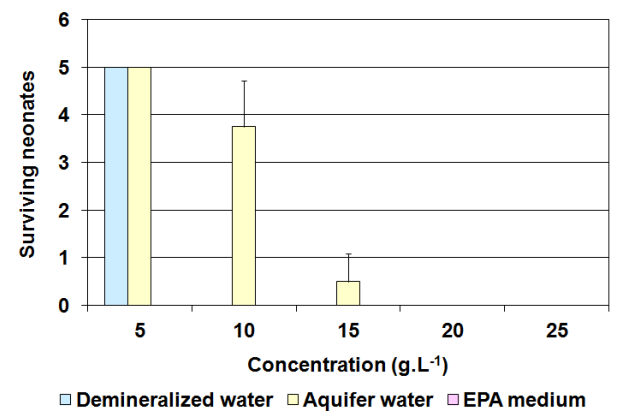

Figure 3. Results of bioassays with M. eugeniae and increasing concentrations of $\mathrm{NaCl}$ dissolved in three different culture media.

\subsection{Bioassays with Natural Salts Dissolved in Aquifer Water}

The survival of neonates of $D$. menucoensis at different concentrations was significantly different $(\mathrm{H}=15.93 ; \mathrm{p}=$ 0.0053) (Fig. 4). The post-test showed that treatments with 5 and 20 g.L - $^{-1}$ were similar to each other, with a mean survival of 2.5 and 3.25 neonates, respectively, but they differed from those performed at 10 and 15 g. $\mathrm{L}^{-1}$, in which the survival was almost complete. The treatment at 25 g. $\mathrm{L}^{-1}$ was also different, because no neonates survived. At this concentration, all the specimens died $24 \mathrm{~h}$ after the assay began.

Bioassays with $M$. eugeniae at different concentrations did not differ, although the value of the statistic was very close to the significance value $(H=19 ; p=0.0576)$. Neonates of this species were found to be more tolerant to both low and high salinity, because survival was complete up to 20 g. $\mathrm{L}^{-1}$, while at the highest concentration $\left(25 \mathrm{~g} . \mathrm{L}^{-1}\right)$, $40 \%$ of the specimens survived (Fig. 4 ).

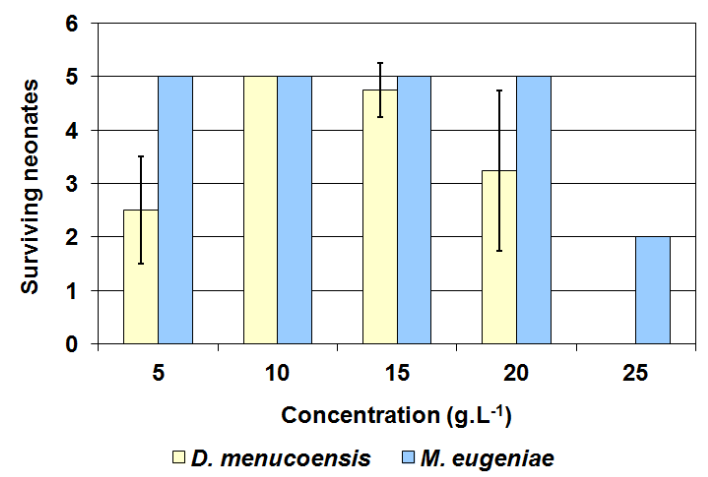

Figure 4. Results of bioassays with D. menucoensis and M. eugeniae using aquifer water and increasing concentrations of salts obtained from the natural environment. 


\section{Discussion}

\subsection{Evaluation of the Efficiency of Three Different Culture Media}

The survival of neonates of both species was higher in solutions prepared with water from the aquifer underlying the city of Santa Rosa. This water is characterized by its poor quality, by having high degree of salinity and mineralization. The level of solutes is so high that this water is currently not considered safe for human consumption and the city is supplied by aqueducts that bring water from other sources.

In contrast to expectations, the survival of neonates of $D$. menucoensis was higher in demineralized water than in EPA medium, although this medium was formulated specifically for breeding other species of the genus Daphnia and is widely used, for example, to maintain cultures $D$. magna, as we do in our laboratory.

Although $M$. eugeniae is a widely tolerant species and in nature it is found in water with dissolved solid concentrations much higher than those tolerated by $D$. menucoensis [8, 9, 16, 21, 31], in these bioassays, their neonates only survived up to salinity levels of 15 g.L - $^{-1}$, also in aquifer water. Although the neonates of this species survived in demineralized water at 5 g.L $\mathrm{L}^{-1}$, EPA medium, which is not specifically formulated for species of this genus, seemed to be harmful, since there were no survivors even at the lowest $\mathrm{NaCl}$ concentration.

The comparison of the behavior of neonates of both species in the two media in which there was greater survival (demineralized water and aquifer water) shows that the latter is more efficient. This may be because of the analytical grade of $\mathrm{NaCl}$ used to prepare the solutions. Thus, the absence of other electrolytes in demineralized water, necessary to maintain the balance of the internal medium, was detrimental to neonates; conversely, their presence in the aquifer water favored survival.

These results are consistent with those obtained in previous series of acute bioassays. Using salts obtained from the natural environment and dissolved in demineralized water, [32] verified that the survival of neonates was possible up to $24 \mathrm{~g} . \mathrm{L}^{-1}$ in the case of D. menucoensis and 31 g. $\mathrm{L}^{-1}$ in that of $M$. eugeniae. In other bioassay series, [33] used reagents of analytical grade dissolved in demineralized water, and found that the survival of the neonates of both species was significantly lower. These results demonstrate that, to maintain homeostasis, the presence of other solutes in the culture medium is necessary. These are present both in the mixture of natural salts and water from the aquifer, but not in demineralized water or pure reagents.

Considering that most of the Pampean lakes, which both species inhabit, are fed in a large proportion by groundwater inputs [16, 21, 29, 38], it can be concluded that aquifer water represents relatively well the features found under natural conditions. From this, it follows that aquifer water is suitable for growing native cladocerans, with the precaution of sterilizing prior to use and accounting for its salinity at all concentrations tested.

\subsection{Bioassays with Natural Salts Dissolved in Aquifer Water}

Considering the efficiency of aquifer water and that [32] demonstrated high survival using salts obtained from the natural environment (dissolved in demineralized water), we decided to test if the combination of both elements (natural salts dissolved in aquifer water) could be the optimal combination for growing these halophilic cladocerans.

While at intermediate salinities the survival of neonates of D. menucoensis was almost complete, in the bioassays with 5 g. $\mathrm{L}^{-1}$ only $50 \%$ of the specimens survived. This is consistent with the results obtained by [32], who also found a relative increase in mortality when salinities lower than 5 g. $\mathrm{L}^{-1}$ were tested. In our bioassays, the tolerance at $25 \mathrm{~g} . \mathrm{L}^{-1}$ was null, which is different than the results of [32], since these authors found some survival (40\%) in bioassays at 24 g. $\mathrm{L}^{-1}$.

The neonates of $M$. eugeniae were more tolerant to higher salinity, since there was only moderate mortality in bioassays at the highest concentration. This greater tolerance, which coincides with previous information collected in natural environments, is also consistent with previous laboratory studies [32], in which it was also found that the mortality of neonates began to be apparent at a salinity of 24 g. $\mathrm{L}^{-1}$.

These results confirm that the combination of natural salts and aquifer water is suitable for assessing the salinity tolerance of neonates of these two species, since survival was found in the known range for both species under natural conditions and in previous laboratory studies. However, considering that the two components used, i.e. natural salts and aquifer water, would provide other necessary ions for neonate homeostasis, the role of the former variable seems more important, since the results were practically the same as those obtained when the same salts were dissolved in demineralized water [32].

Considering the high survival of neonates that was found compared to that obtained in bioassays with analytical grade $\mathrm{NaCl}$, it is remarkable the importance of the use of these salts to assess the tolerance of halophilic endemic cladocerans from central Argentina because they are representative of the chemistry of water bodies inhabited by these animals.

\section{Conclusions}

Despite the EPA medium was specifically formulated for breeding some species of the genus Daphnia, was not adequate to breed the halophilic D. menucoensis. This medium seemed to be detrimental for $M$. eugeniae since no survivors were registered at any concentration.

Despite its low quality due to its highly mineralization, the water from the aquifer underlying Santa Rosa city is adequate for the breeding of native halophilic cladocerans, due to the high survival of neonates of both species in solutions prepared with this water. This water probably 
provides other necessary ions for neonate homeostasis.

Our results confirm that the combination natural saltsaquifer water is suitable for assessing the salinity tolerance of neonates of these two species. However, comparing the two components (natural salts and aquifer water), the former seems more important, since the results of this work were similar as those obtained when the same salts were dissolved in demineralized water. The importance of the use of these salts to breed neotropical halophilic cladocerans is remarkable since the survival of neonates was higher than we used analytical grade reagents, probably because provide other solutes necessary to maintain neonates homeostasis.

\section{References}

[1] J. Paggi, "Cladocera (Anomopoda and Ctenopoda)", in Biodiversity of Argentinian Arthropods, S. Coscarón and J. J. Morrone, Eds. Sur Editions, La Plata, pp. 507-518, 1998. (In Spanish).

[2] G. Boxshall, and D. Defaye, "Global diversity of copepods (Crustacea: Copepoda) in freshwater", Hydrobiologia, vol. 595, pp. $195-207,2008$.

[3] L. Forró, N. Korovchinsky, A. Kotov and A. Petrusek, "Global diversity of cladocerans (Cladocera; Crustacea) in freshwater”. Hydrobiologia, vol. 595, pp. 177-184, 2008.

[4] P. A. Battistoni, "Copepoda", in Biodiversity of Argentinian Arthropods, S. Coscarón and J. J. Morrone, Eds. Sur Editions, La Plata, pp. 519-530, 1998. (In Spanish).

[5] S. Menu-Marque, and C. Locascio de Mitrovich, "Geographical distribution of the species of genus Boeckella (Copepoda, Calanoida, Centropagidae) in the Argentina Republic”, Physis, vol. 56 B, pp. 1-10, 1998. (In Spanish).

[6] S. Menu-Marque, J. Morrone and C. Locascio de Mitrovich, "Distributional patterns of the south american species of Boeckella (Copepoda: Centropagidae): a track analysis". J. Crustacean Biol., vol. 20, n 2, pp. 262-272, 2000.

[7] S. Adamowicz, P. Hebert and M. C. Marinone, "Species diversity and endemism in the Daphnia of Argentina: a genetic investigation", Zool. J. Linn. Soc. London, vol. 140, pp. 171-205, 2004.

[8] S. A. Echaniz, A. M. Vignatti, S. José de Paggi , J. C. Paggi and A. Pilati, "Zooplankton seasonal abundance of South American saline shallow lakes", Int. Rev. Hydrobiol., vol. 91, $\mathrm{n}^{\circ} 1$, pp. 86-100, 2006.

[9] A. M. Vignatti, S. A. Echaniz and M. C. Martín, "The zooplankton of shallow lakes of different salinity and trophic status in the Pampean semi-arid region (La Pampa, Argentina)", Gayana, vol. 71, n 1, pp. $38-48,2007$. (In Spanish).

[10] A. M.Vignatti, J. C Paggi, G. C. Cabrera and S. A. Echaniz, "Zooplankton diversity and its relationship with environmental changes after the filling of a temporary saline lake in the semi-arid region of La Pampa (Argentina)", Lat. Am. J. Aquat. Res., vol. 40, n 4, pp. 1005-1016, 2012.

[11] M. Scheffer, "Ecology of shallow lakes". Chapman \& Hall, London, 1998.
[12] E. Jeppesen, M. Søndergaard, E. Kanstrup, I. Pedersen, R. Henriksen, M. Hammershøj, E., Mortensen, J. Jensen and A. Have, "Does the impact of nutrients on the biological structure and function of brackish and freshwater lakes differ?", Hydrobiologia, vol. 275/376, pp. 15-30, 1994.

[13] E. Jeppesen, M. Søndergaard, A. Pedersen, K. Jürgens, A. Strzelczak, T. Lauridsen, and L. Johansson, "Salinity induced regime shift in shallow brackish lagoons, Ecosystems, vol. 10, pp. 47-57, 2007.

[14] R. H. Peters, "Metabolism in Daphnia", Mem. Inst. It. Idrobiol. vol. 45, pp. 193-243, 1987.

[15] M. Teschner, "Effects of salinity on the life history and fitness of Daphnia magna: variability within and between populations", Hydrobiologia, vol. 307, pp. 33-41, 1995.

[16] S. A. Echaniz, "Composition and abundance of zooplankton in lakes of different ionic composition of the province of $\mathrm{La}$ Pampa”. PhD dissertation. National University of Río Cuarto, 2010. (In Spanish).

[17] S. A. Echaniz, A. M. Vignatti, G. C. Cabrera and S. B. José de Paggi, "Zooplankton richness, abundance and biomass of two hypertrophic shallow lakes with different salinity", Biota Neotrop., vol. 12, $\mathrm{n}^{\circ}$ 2, pp. 37-44, 2012.

[18] M. Alonso, "Crustacea, Branchipoda", in Iberic fauna, Ramos, M. et. al. Eds, National Museum of Naturals Sciences. CSIC. Madrid, vol. 7, pp. 486, 1996. (In Spanish).

[19] L. Forró, "A new species of Moina from Australia (Crustacea: Cladocera)". Acta zool. hung. Vol. 31, pp. 111-118, 1985.

[20] C. Goulden, "The systematics and evolution of the Moinidae", T. Am. Phil. Soc., vol. 58, n 6, pp. 1-101, 1968.

[21] S. A. Echaniz, G. C. Cabrera, C. Rodríguez, and A. M. Vignatti, "Do temporary lakes vary from year to year? A comparison of limnological parameters and zooplankton from two consecutive annual cycles in an Argentine temporary saline lake", Int. J. of Aquat. Sci., vol. 4, n 1, pp. 44-61, 2013.

[22] S. E. Mitchell and W. Lampert, "Temperature adaptation in a geographically widespread zooplankter, Daphnia magna", J. of Evol. Biol., vol. 13, pp. 371-382, 2000.

[23] F. Martínez-Jerónimo and L. Martínez-Jerónimo, “Chronic effect of $\mathrm{NaCl}$ salinity on a freshwater strain of Daphnia magna Straus (Crustacea: Cladocera): A demographic study", Ecotox. Environ. Saf., vol. 67, pp. 411-416, 2007.

[24] M. Ghazy, M. Habashy, F. Kossa and E. Mohammady, "Effects of Salinity on Survival, Growth and Reproduction of the Water Flea, Daphnia magna", Nature and Science, vol. 7 , $\mathrm{n}^{\circ} 11$, pp. 28-42, 2009.

[25] C. Hall and C. Burns, "Responses of crustacean zooplankton to seasonal and tidal salinity changes in the coastal Lake Waihola, New Zealand”, New Zeal. J. Mar. Fresh, vol. 37, pp. 31-43, 2003.

[26] I. Heine-Fuster, C. Vega Retter, P. Sabat and R. Ramos Jiliberto, "Osmoregulatory and demographic responses to salinity of the exotic cladoceran Daphnia exilis", J. Plankton Res., vol. 32, n 10, pp. 1405-1411, 2010. 
[27] F. Martínez-Jerónimo and F. Espinosa-Chávez, "Notes on the reproduction and survival of Moina hutchinsoni Brehm, 1937 (Moinidae: Anomopoda) grown in media of varying salinity", Aquat. Ecol., vol. 39, pp. 113-118, 2005.

[28] S. S. Sarma, E. S. Nandini, J. Morales-Ventura, I. Delgado-Martínez and L. González-Valverde, "Effects of $\mathrm{NaCl}$ salinity on the population dynamics of freshwater zooplankton (rotifers and cladocerans)", Aquat. Ecol., vol. 40, pp. 349-360, 2006.

[29] S. A. Echaniz and A. M. Vignatti, "Seasonal variation and influence of turbidity and salinity on the zooplankton of a saline lake in central Argentina", Lat. Am. J. of Aquat. Res., vol. $39, \mathrm{n}^{\circ} 2$, pp. 306-315, 2011.

[30] S. A Echaniz, A. M. Vignatti, S. B. José de Paggi and G. C. Cabrera, "The model of alternative states of shallow lakes in La Pampa: comparison of Bajo de Giuliani and El Carancho", Proceedings of $3^{\circ}$ Pampean Water Congress, pp. 45-53, 2010. (In Spanish).

[31] A. Vignatti, R. Festa, G. Cabrera and S. Echaniz, "Comparison after a decade of limnological parameters, zooplankton richness and abundance of a shallow saline lake of the province of La Pampa", BioScriba, vol. 5, $\mathrm{n}^{\circ}$ 1, pp. 23-35, 2012. (In Spanish).

[32] A. M. Vignatti, J. C. Paggi, S. A. Echaniz and G. C. Cabrera,
"Salinity tolerance of two halophilic autochthonous cladocerans: Daphnia menucoensis y Moina eugeniae (Artropoda, Crustacea)", Biol. Acuát., vol. 27, pp. 219-231, 2012. (In Spanish).

[33] G. Cabrera, A. Vignatti and S. Echaniz, "Acute Effects of $\mathrm{NaCl}$ and $\mathrm{Na}_{2} \mathrm{SO}_{4}$ on Daphnia menucoensis Paggi, 1996 and Moina eugeniae Olivier, 1954 (Crustacea, Cladocera)", Res. in Zool., vol. $4, \mathrm{n}^{\circ} 1$, in press.

[34] C. Weber (ed.), "Methods for measuring the acute toxicity of effluents and receiving waters to freshwater and marine organisms". US EPA/600/4-90/027F, Ohio, 1993.

[35] R. Sokal and F. Rohlf, "Biometrics. Principles and statistical methods in Biol. Res", Ed. Blume, Barcelona, 1995. (In Spanish).

[36] J. H. Zar, "Biostatistical analysis", $3^{\circ}$ Ed. Prentice Hall, New Jersey, 1996.

[37] Ø. Hammer, D. Harper and P. Ryan, "PAST: Paleontological Statistics Software Package for Education and Data Analysis", Palaeont. Electr., vol. 4, n 1, pp. 1-9, 2001.

[38] S. A. Echaniz and A. M. Vignatti, "Trophic status of shallow lakes of La Pampa (Argentina) and its relation with the land use in the basin and nutrient internal load", J. Environ. Protec., vol. 4, pp. 51-60, 2013. 